A C G publications

\title{
Neoflavonoids from the Heartwood of Dalbergia melanoxylon Zhangjun Xu$\odot^{1}$, Yang Liu $\odot^{1}$, Xiaowei Meng $\odot^{2}$, Li Yang $\odot^{1}$, Feng Shao $\odot^{1}$, Ronghua Liu $\oplus^{2 *}$ and Lanying Chen $\oplus^{3 *}$
}

\author{
${ }^{1}$ Key Laboratory of Modern Preparation of TCM, Ministry of Education \\ Jiangxi University of Chinese Medicine,Nanchang, Jiangxi 330004, P. R.China \\ ${ }^{2}$ The College of Pharmacy, Jiangxi University of Chinese Medicine, \\ Nanchang, Jiangxi 330004, P. R. China \\ ${ }^{3}$ National Pharmaceutical Engineering Center for Solid Preparation in Chinese Herbal Medicine, Jiangxi \\ University of Chinese Medicine, \\ Nanchang, Jiangxi 330004, P. R.China
}

(Received May 10, 2021; Revised June 25, 2021; Accepted June 26, 2021)

\begin{abstract}
A new neoflavonoid, (1R, 8R, 9R)-pterolinuse K (1) and six known neoflavonoids (2-7) were obtained from the heartwood of Dalbergia melanoxylon. The structure of the new neoflavonoid was elucidated by extensive NMR investigation, and X-ray crystallographic analysis. Compounds 3 and 6 showed anti-inflammatory activity with IC50 values $23.14 \pm 0.30$ and $19.46 \pm 1.02 \mu \mathrm{M}$, respectively. Compounds 2-4, 6, 7 were showed cytotoxicity on Caco-2, MDA-MB-468, MDA-MB-231, CT26 cell lines. Moreover, compounds 2, 4 exhibited the significant activity in MDA-MB-231 cell lines with IC50 values $7.54 \pm 1.50$ and $7.23 \pm 0.40 \mu \mathrm{M}$, respectively.
\end{abstract}

Keywords: Dalbergia melanoxylon; neoflavonoids; anti-inflammatory activity; anti-tumor activity. @ 2021 ACG Publications. All rights reserved.

\section{Plant Source}

The heartwoods of Dalbergia melanoxylon Guill. \& Perr. (D. melanoxylon) were purchased from Fang Cheng Gang market, Guangxi Province, China, in July 2014 and identified by Professor Feng Xu at the product quality inspection center of Guangxi University. A voucher specimen (No. Liu-20140702) was deposited in the Key Laboratory of Innovation Drug and Efficient Energy-saving Pharmaceutical Equipment, Jiangxi University of Traditional Chinese Medicine.

\footnotetext{
* Corresponding author: E- Mail: rhliu@163.com (R. -H. Liu) and cly5831@163.com (L. -Y. Chen)
} 


\section{Neoflavonoids from Dalbergia melanoxylon}

\section{Previous Studies}

Neoflavonoids were belong to the flavonoids class with the structural of C6-C3-C6, it contains 4-arylcoumarins, 4-arylchromanes, dalbergiones, and dalbergiquinols [1]. The neoflavonoids were reported to display a variety of pharmacologicalactivities, for example anti-osteoporosis [2], anti-inflammatory [3], anti-tumor [4], anti-androgen [5] and cardioprotective effects [6-9]. D. melanoxylon belongs to the family Leguminosae and subfamily Papilionaidae, is a heavily branched deciduous tree [10]. It has a wide range of occurrence in sub-Saharan Africa [11]. D. melanoxylon have been used for treating abdominal pain, gonorrhoea, joint pain and bronchitis [12-13].

\section{Present Study}

The powdered heartwood of D. melanoxylon $(50.0 \mathrm{~kg})$ was extracted by infusion with $70 \%$ ethanol at roomtemperature (24h, 3 times). Next, the extraction was filtered and the solvent was evaporated under reduced pressure in a rotary evaporation equipment (Buchi, Switzerland). And then, the obtained extract (13.9 $\mathrm{kg}$ ) was dissolved in distilled $\mathrm{H}_{2} \mathrm{O}$ and successively partitioned with $\mathrm{CH}_{2} \mathrm{Cl}_{2}$, EtOAc and $n$-BuOH. The $\mathrm{CH}_{2} \mathrm{Cl}_{2}$ portion $(8.5 \mathrm{~kg}$ ) was subjected to silica gel CC (column chromatography) using petroleum ether-EtOAc (from 50:1 to $1: 5, v / v)$ as the elution to yield 22 fractions (Frs.1-Frs.22). Frs.7 (447.4 g) was purified by silica gel column to give six fractions (Frs.7.A-Frs.7.F), through gradient elution with changing ratios of $\mathrm{CH}_{2} \mathrm{Cl}_{2}-\mathrm{MeOH}$ from 100:1-10:1(v/v). Frs.7.C (196.9g) was purified by Sephadex LH-20 CC eluted with $\mathrm{CH}_{2} \mathrm{Cl}_{2}-\mathrm{MeOH}(1: 1$, $v / v)$ to yield three fractions (Frs.7.C.1-Frs.7.C.3). Frs.7.C.2 (7.5 g) was separated by silica gel column (petroleum ether-acetone, 20:1-5:1) to yield 3 (1.7 g). Frs.7.C.3 (7.5 g) was separated by silica gel column (petroleum ether-acetone, 20:1-2:1) to yield 4 (11.2 g). Frs.9 (96.9 g) was fractionated via silica gel CC eluted with $\mathrm{CH}_{2} \mathrm{Cl}_{2}-\mathrm{MeOH}$ (from 400:1-10:1, v/v) to yield three fractions (Frs.9.A-Frs.9.C). Frs.9.B (45.8 g) was further fractionated via silica gel CC eluted with petroleum ether-acetone (from 10:1-2:1, v/v) to obtain 5 (16.1 mg). Frs.13 (227.6 g) was fractionated via silica gel CC eluted with $\mathrm{CH}_{2} \mathrm{Cl}_{2}-\mathrm{MeOH}$ (from 100:1-10:1, v/v) to yield three fractions (Frs.13.A-Frs.13.C). Frs.13.B (89.3 g) was further fractionated via silica gel CC eluted with $\mathrm{CH}_{2} \mathrm{Cl}_{2}-\mathrm{MeOH}$ (from 200:1-100:1, v/v) to obtain 2 (20.1 g). Frs.14 (303.7 g) was loaded ODS column chromatography with $\mathrm{MeOH}-\mathrm{H}_{2} \mathrm{O}$ gradient elution to give (from 30:70 to 50:50, v/v) to yield 9 fractions (Frs.14.A-Frs.14.I). Frs.14.C (5.4 g) was further fractionated via silica gel CC eluted with $\mathrm{CH}_{2} \mathrm{Cl}_{2}-\mathrm{MeOH}$ (from 1000:1-100:1, v/v) to obtain 6 (56.8 mg). Frs.14.I (23.6 g) was fractionated via silica gel CC eluted with $\mathrm{CH}_{2} \mathrm{Cl}_{2}-\mathrm{MeOH}$ (from 100:1-10:1, v/v) to yield 4 fractions (Frs.14.I.1-Frs.14.I.4). Frs.14.I.2 (953.5 mg) was further fractionated via silica gel $\mathrm{CC}$ eluted with $\mathrm{CH}_{2} \mathrm{Cl}_{2}-\mathrm{MeOH}$ (from 1000:1-200:1, v/v) to obtain 7 (58.2 $\mathrm{mg}$ ).Frs.15 (83.2 g) was loaded ODS column chromatography with $\mathrm{MeOH}-\mathrm{H}_{2} \mathrm{O}$ gradient elution to give (from 30:70 to 50:50, $v / v$ ) to yield 5 fractions (Frs.15.A-Frs.15.E). Frs.15.A(1.8 g) was purified by Sephadex LH-20 $\mathrm{CC}$ eluted with $\mathrm{CH}_{2} \mathrm{Cl}_{2}-\mathrm{MeOH}(1: 1, v / v)$ to yield 2 fractions (Frs.15.A.1-Frs.15.A.2). Frs.15.A.1 (452.7 mg) was separated by preparative HPLC eluted with $\mathrm{MeOH}-\mathrm{H}_{2} \mathrm{O}(32: 68, v / v)$ to yield $\mathbf{1}\left(20.5 \mathrm{mg}, t_{\mathrm{R}}=36.4 \mathrm{~min}\right)$.

$(1 R, 8 R, 9 R)$-pterolinuse $K(\mathbf{l})$ : Colorless crystals $(\mathrm{MeOH}) ;[\alpha]_{\mathrm{D}}{ }^{24}=+22.7(c=0.1, \mathrm{MeOH}) . \mathrm{UV}(\mathrm{MeOH}) \lambda_{\max }$ : 290, 250, $240 \mathrm{~nm}, \quad \mathrm{IR} \quad(\mathrm{KBr}) \quad v_{\max } \quad 3372.2, \quad 1660.1, \quad 1453.1, \quad 1452.9, \quad 1413.3 \quad \mathrm{~cm}^{-1} . \quad \mathrm{CD}$ $(\mathrm{MeOH}) \lambda_{\max }(\Delta \varepsilon) 234(+1.41), 283(+1.34)$; HR-ESI-MS $m / z \quad 303.1224 \quad\left([\mathrm{M}+\mathrm{H}]^{+}\right.$calcd for $\mathrm{C}_{17} \mathrm{H}_{19} \mathrm{O}_{5}$, 
303.1227). ${ }^{1} \mathrm{H}-\mathrm{NMR}$ (DMSO- $d_{6}, 600 \mathrm{MHz}$ ) and ${ }^{13} \mathrm{C}-\mathrm{NMR}$ (DMSO- $d_{6}, 150 \mathrm{MHz}$ ): see Table $\mathrm{S} 1$ in supporting information.

In our ongoing project of the investigation on the chemical constituents and bioactive of D. melanoxylon, one new neoflavonoid (1) and six known neoflavonoids (2-7) were obtained from the heartwood of $D$. melanoxylon (Figure 1).
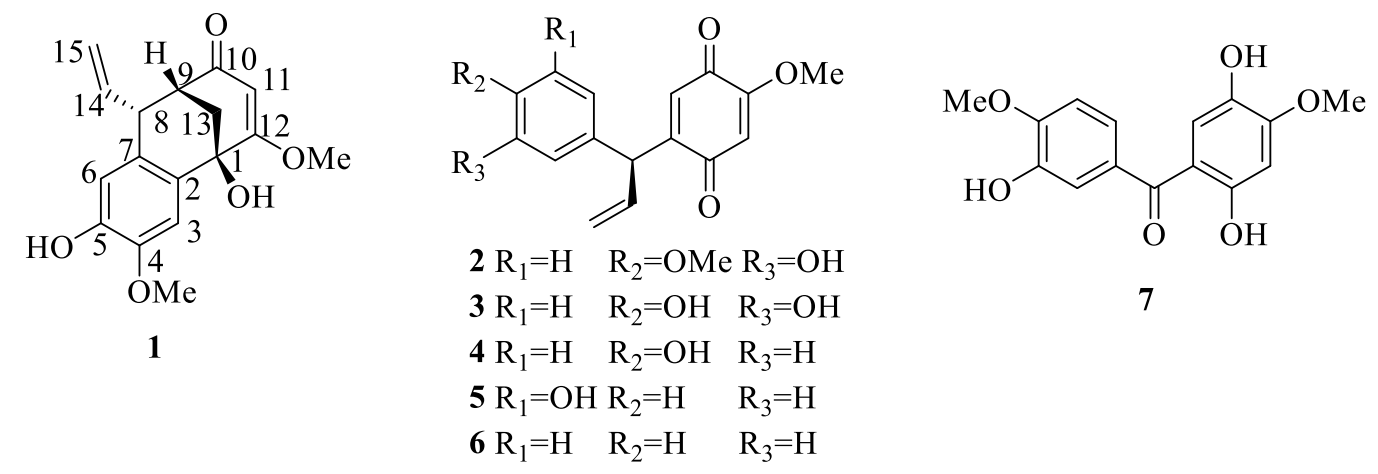

Figure 1. Structures of compounds 1-7

Compound $\mathbf{1}$ was a colorless crystals, with a molecular formula of $\mathrm{C}_{17} \mathrm{H}_{18} \mathrm{O}_{5}$ as deduced from the (+)-HR-ESI-MS $m / z 303.1224\left([\mathrm{M}+\mathrm{H}]^{+}\right.$calcd for $\left.\mathrm{C}_{17} \mathrm{H}_{19} \mathrm{O}_{5}, 303.1227\right)$, inferring 9 degree of unsaturation. The ${ }^{1} \mathrm{H}-\mathrm{NMR}$ spectrum exhibited the signals (Table 1) of two hydroxyls at $\delta_{\mathrm{H}} 5.89(1 \mathrm{H}, \mathrm{s}, 1-\mathrm{OH})$ and $8.93(1 \mathrm{H}, \mathrm{s}$, 5-OH), two methoxy groups at $\delta_{\mathrm{H}} 3.62\left(3 \mathrm{H}, \mathrm{s}, 12-\mathrm{OCH}_{3}\right)$ and $3.73\left(3 \mathrm{H}, \mathrm{s}, 4-\mathrm{OCH}_{3}\right)$, two aromatic protons at $\delta_{\mathrm{H}}$ $7.15(1 \mathrm{H}, \mathrm{s}, \mathrm{H}-3)$ and $6.51(1 \mathrm{H}, \mathrm{s}, \mathrm{H}-6)$, four olefinic protons at $\delta_{\mathrm{H}} 5.14(1 \mathrm{H}, \mathrm{s}, \mathrm{H}-11), 5.35(1 \mathrm{H}, \mathrm{ddd}, J=16.9$, $10.1,8.1 \mathrm{~Hz}, \mathrm{H}-14), 5.20(1 \mathrm{H}, \mathrm{d}, J=16.9 \mathrm{~Hz}, \mathrm{H}-15 \mathrm{a})$ and $5.14(2 \mathrm{H}, \mathrm{m}, \mathrm{H}-15 \mathrm{~b})$, two methines at $\delta_{\mathrm{H}} 3.68(1 \mathrm{H}, \mathrm{t}$, $J=8.1 \mathrm{~Hz}, \mathrm{H}-8)$ and $2.83(1 \mathrm{H}, \mathrm{s}, \mathrm{H}-9)$, diastereotopic methylene protons at $\delta_{\mathrm{H}} 2.44(1 \mathrm{H}, \mathrm{d}, J=12.0 \mathrm{~Hz}, \mathrm{H}-13 \mathrm{a})$ and $2.15(1 \mathrm{H}, \mathrm{d}, J=12.0 \mathrm{~Hz}, \mathrm{H}-13 \mathrm{~b})$. Inspection of its ${ }^{13} \mathrm{C}-\mathrm{NMR}$ spectra exhibited17 carbon resonances assignable to two methoxy groups at $\delta_{\mathrm{C}} 56.9\left(4-\mathrm{OCH}_{3}\right)$ and $56.2\left(12-\mathrm{OCH}_{3}\right)$, six aromatic carbons at $\delta_{\mathrm{C}} 132.0$ (C-2), 109.2 (C-3), $146.4(\mathrm{C}-4), 146.3$ (C-5), 115.8 (C-6) and 127.7 (C-7), two double bonds at $\delta_{\mathrm{C}} 100.6(\mathrm{C}-11)$, $183.3(\mathrm{C}-12), 140.0$ (C-14) and $117.2(\mathrm{C}-15)$, four methines at $\delta_{\mathrm{C}} 69.5(\mathrm{C}-1), 45.0(\mathrm{C}-8), 48.8(\mathrm{C}-9)$ and 40.7 (C-13), one conjugated ketone at $\delta_{\mathrm{C}} 197.5$ (C-10) (Table 1). These data were similar with those of (1S, 8R, $9 S)$-1, 5-dihydroxy-4,12-dimethoxy-8-vinyl-tricyclo[7.3.1. $\left.0^{2,7}\right]$ trideca-2,4,6,11 tetraen-10-one skeleton [14]. The HMBC correlation of $\mathrm{H}-13 \mathrm{a}\left(\delta_{\mathrm{H}} 2.44\right)$ and $\mathrm{H}-13 \mathrm{~b}\left(\delta_{\mathrm{H}} 2.15\right)$ with C-2 $\left(\delta_{\mathrm{C}} 132.0\right), \mathrm{C}-8\left(\delta_{\mathrm{C}} 45.0\right), \mathrm{C}-10\left(\delta_{\mathrm{C}}\right.$ $197.5)$ and $\mathrm{C}-12\left(\delta_{\mathrm{C}} 183.3\right)$ have confirmed the methylene was linked to $\mathrm{C}-1\left(\delta_{\mathrm{C}} 69.5\right)$ and $\mathrm{C}-9\left(\delta_{\mathrm{C}} 48.8\right)$, two hydroxy groups were attached to $\mathrm{C}-1$ and $\mathrm{C}-5$, respectively. In HMBC spectrum, cross-peaks for 1-OH $\left(\delta_{\mathrm{H}}\right.$ $5.89) / \mathrm{C}-1\left(\delta_{\mathrm{C}} 69.5\right), \mathrm{C}-2\left(\delta_{\mathrm{C}} 132.0\right), \mathrm{C}-12\left(\delta_{\mathrm{C}} 183.3\right)$ and $\mathrm{C}-13\left(\delta_{\mathrm{C}} 40.7\right), 5-\mathrm{OH}\left(\delta_{\mathrm{H}} 5.59\right) / \mathrm{C}-5\left(\delta_{\mathrm{C}} 146.3\right)$ and $\mathrm{C}-6\left(\delta_{\mathrm{C}} 115.8\right) .4-\mathrm{OCH}_{3}\left(\delta_{\mathrm{H}} 3.73\right)$ was located at C-4 $\left(\delta_{\mathrm{C}} 146.4\right)$ and $12-\mathrm{OCH}_{3}\left(\delta_{\mathrm{H}} 3.62\right)$ was located at C-12 $\left(\delta_{\mathrm{C}} 183.3\right)$ observed in HMBC and HSQC. The relative configuration was assigned from the ROESY spectrum, in which $\mathrm{H}-13\left[\delta_{\mathrm{H}} 3.68(1 \mathrm{H}, \mathrm{t}, J=8.1 \mathrm{~Hz})\right]$ showed correlation with $\mathrm{H}-8$ suggesting that $\mathrm{H}-13\left[\delta_{\mathrm{H}} 2.44(1 \mathrm{H}, \mathrm{d}\right.$, $J=12.0 \mathrm{~Hz}), 2.15(1 \mathrm{H}, \mathrm{d}, J=12.0 \mathrm{~Hz})]$ was on the same side with $\mathrm{H}-8\left(\delta_{\mathrm{H}} 3.51\right)$ (Figure 2). The absolute configuration of compound $\mathbf{1}$ was also determined to be $(1 R, 8 R, 9 R)$-pterolinuse $\mathrm{K}$ by X-ray crystallography (CCDC: 2052275) (Figure 3).

The six known neoflavonoids (2-7) were identified as (S)-3'-hydroxy-4,4'-dimethoxydalbergione (2)[15],
(S)-3',4'dihydroxy-4-methoxydalbergione
(3)[16],
(S)-4'-hydroxy-4-methoxydalbergione
(4)[17], 


\section{Neoflavonoids from Dalbergia melanoxylon}

(S)-3'-hydroxy-4-methoxydalbergione (5)[16], (S)-4-methoxydalbergione (6)[17], melanoxoin (7)[18], by comparing the observed and reported NMR data.

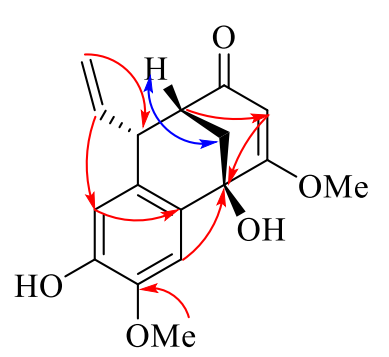

\section{$\Upsilon \mathrm{HMBC} \frown \mathrm{ROESY}$}

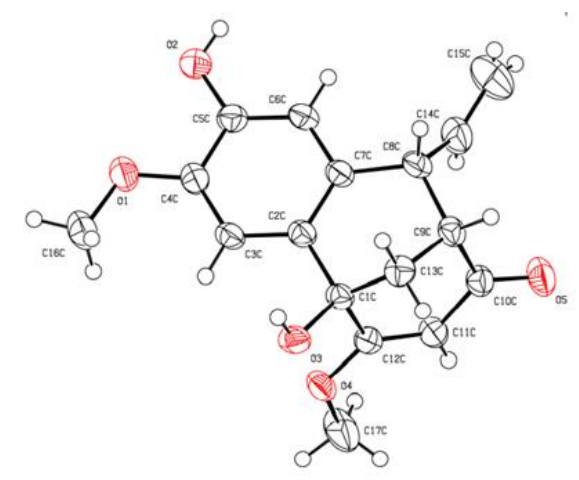

Figure 2. Selected HMBC and ROESY Figure 3. ORTEP drawing of compound 1 correlations of correlations of compound 1

The isolates 1-7 were assessed anti-inflammatory properties against lipopolysaccharide (LPS)-activated RAW 264.7 cells in vitro assay. Among all tested compounds, 3 and $\mathbf{6}$ showed moderate anti-inflammatory activity with $\mathrm{IC}_{50}$ values $23.14 \pm 0.30$ and $19.46 \pm 1.02 \mu \mathrm{M}$, respectively (Table 1). Compounds 3 and $\mathbf{6}$ have similar chemical structure and $\mathbf{6}$ showed better activity, which suggested that the hydroxy group in C-3' and C-4' might weaken the anti-inflammatory activity of neoflavonoids.

Table 1. Cytotoxicities and anti-inflammatory activities $\left(\mathrm{IC}_{50}\right.$ in $\left.\mu \mathrm{M}\right)$ of compounds

\begin{tabular}{ccc}
\hline Compound & Cytotoxicity & Anti-inflammatory activity \\
\hline quercetin & $>100$ & $17.92 \pm 0.92$ \\
$\mathbf{1}$ & $>100$ & $>100$ \\
$\mathbf{2}$ & $26.09 \pm 1.99$ & - \\
$\mathbf{3}$ & $>100$ & $23.14 \pm 0.30$ \\
$\mathbf{4}$ & $22.24 \pm 2.30$ & - \\
$\mathbf{5}$ & $>100$ & $>100$ \\
$\mathbf{6}$ & $>100$ & $19.46 \pm 1.02$ \\
$\mathbf{7}$ & $98.48 \pm 20.85$ & $89.31 \pm 7.51$ \\
\hline
\end{tabular}

Table 2. Anti-tumor activities ( $\mathrm{IC}_{50}$ in $\mu \mathrm{M}$ ) of compounds

\begin{tabular}{ccccc}
\hline Compound & Caco-2 & MDA-MB-468 & MDA-MB-231 & CT26 \\
\hline $\mathbf{5 - F U}$ & $190.32 \pm 24.13$ & $149.09 \pm 21.02$ & $48.84 \pm 14.84$ & $61.89 \pm 16.35$ \\
$\mathbf{1}$ & $>100$ & $>100$ & $>100$ & $>100$ \\
$\mathbf{2}$ & $15.14 \pm 1.13$ & $40.90 \pm 7.56$ & $7.54 \pm 1.50$ & $23.10 \pm 1.20$ \\
$\mathbf{3}$ & $26.46 \pm 3.76$ & $37.52 \pm 1.70$ & $16.60 \pm 2.98$ & $52.38 \pm 16.51$ \\
$\mathbf{4}$ & $11.42 \pm 1.08$ & $23.66 \pm 1.58$ & $7.23 \pm 0.40$ & $24.43 \pm 0.90$ \\
$\mathbf{5}$ & $>100$ & $>100$ & $>100$ & $>100$ \\
$\mathbf{6}$ & $32.92 \pm 2.34$ & $89.00 \pm 10.90$ & $21.88 \pm 0.63$ & $>100$ \\
$\mathbf{7}$ & $46.89 \pm 2.54$ & $22.14 \pm 1.07$ & $27.31 \pm 1.10$ & $33.83 \pm 0.94$ \\
\hline
\end{tabular}

All isolated neoflavonoids (1-7) from D. melanoxylon were evaluated for their cytotoxic activities on 
Caco-2, MDA-MB-231, MDA-MB-468 and CT26 cell lines by MTT assays. The results revealed that compound 2 and $\mathbf{4}$ showd potent cytotoxic activities against four above cell lines with $\mathrm{IC}_{50}$ values ranging from $7.23 \pm 0.40$ to $40.90 \pm 7.56 \mu \mathrm{M}$, compound $\mathbf{3}$ and 7 displayed moderate cytotoxic activities against four above cell lines with $\mathrm{IC}_{50}$ values ranging from $16.60 \pm 2.98$ to $52.38 \pm 16.51 \mu \mathrm{M}$ (Table 2), which suggested that the hydroxy group might enhance the anti-cancer activity of neoflavonoids. Compounds 2-6 has similar chemical structure but 5 showed no anti-cancer activity. It indicated the hydroxy group in C-3' of $\mathbf{5}$ might weaken anti-cancer activity.

\section{Acknowledgments}

The work was partially supported by the National Natural Science Foundation of China (81660676 and 81360629), the National Key R\&D Program of China (2018YFC1706102) and the Natural Science Foundation of Jiangxi Province (20202BABL216074).

\section{Supporting Information}

Supporting Information accompanies this paper on http://www.acgpubs.org/journal/records -of-natural-products

\section{ORCID}

Zhangjun Xu: 0000-0002-8430-0806

Yang Liu: 0000-0002-0959-3004

Xiaowei Meng: 0000-0003-2956-8460

Li Yang: 0000-0001-9098-694X

Feng Shao:0000-0002-4306-6451

Ronghua Liu: 0000-0001-5623-9000

Lanying Chen: 0000-0001-8115-8114

\section{References}

[1] M. M. Garazd, Y. L. Garazd and V. P. Khilya (2003). Neoflavones.1. Natural distribution and spectral and biological properties, Chem. Nat. Compd+. 39, 54 - 121.

[2] P. Kumar, P. Kushwaha, V. Khedgikar, J. Gautam, D. Choudhary, D. Singh, R. Trivedi and R. Maurya (2014). Neoflavonoids as potential osteogenic agents from Dalbergia sissoo heartwood, Bioorg. Med. Chem. Lett. 24, 2664 - 2668.

[3] C. Lee, J. W. Lee, Q. Jin, D. S. Jang, S. Lee, D. Lee, J. T. Hong, Y. Kim, M. K. Lee and B. Y. Hwang (2013). Inhibitory constituents of the heartwood of Dalbergia odorifera on nitric oxide production in RAW 264.7 macrophages, Bioorg. Med. Chem. Lett. 23, 4263 - 4266.

[4] K. R. Park, H. M. Yun, T. H. Quang, H. Oh, D. S. Lee, Q. S. Auh and E. C. Kim (2016). 4-Methoxydalbergione suppresses growth and induces apoptosis in human osteosarcoma cells in vitro and in vivo xenograft model through down-regulation of the JAK2/STAT3 pathway, Oncotarget 7, 6960 - 6971. 


\section{Neoflavonoids from Dalbergia melanoxylon}

[5] M. Kuroyanagi, A. Ueno, Y. Hirayama, Y. Hirayama, T. Gokita, T. Isiiimaru, S. Kameyama, T. Yanagawa, M. Satake and S. Satake (1996). Anti-androgen active constituents from Dalbergia cochinchinensis PIERRE, Nat. Medicin. 50, 408 - 412.

[6] Y. Liu, N. Zhang, J. W. He, L. Y. Chen, L. Yang, X. W. Meng, F. Shao and R. H. Liu (2021), Two new compounds from the heartwood of Dalbergia melanoxylon and their protective effect on hypoxia/reoxygenation injury in H9c2, Nat. Prod. Commun. 16, 1 -7.

[7] X. X. Lai, N. Zhang, L. Y. Chen, Y. Y. Luo, B. Y. Shou, X. X. Xie and R. H. Liu (2020), Latifolin protects against myocardial infarction by alleviating myocardial inflammatory via the HIF-1 a /NF- к B/IL-6 pathway, Pharm. Biol. 58, 1156 - 1166.

[8] N. Zhang, B. Y. Shou, L. Y. Chen, X. X. Lai, Y. Y. Luo, X. W. Meng and R. H. Liu (2020), Cardioprotective effects of latifolin against doxorubicin-induced cardiotoxicity by macrophage polarization in mice, J. Cardiovasc. Pharmacol. 75, 564 - 572.

[9] Y. Liu, J. C. Shu, M. F. Wang, Z. J. Xu, L. Yang, X. W. Meng, W. B. Duan, N. Zhang, F. Shao, R. H. Liu and L. Y. Chen (2021), Melanoxylonin A-G, neoflavonoids from the heartwood of Dalbergia melanoxylon and their cardioprotective effects, Phytochemistry 189, 112845.

[10] M. Jenkins, S. Oldfield and T. Aylett (2002). International trade in African blackwood, Cambridge, UK: Fauna and Flora International.

[11] R. E. Malimbwi, E. J. Luoga, O. Hofstad, A. G. Mugasha and J. S. Valen (2000). Prevalence and standing volume of Dalbergia melanoxylon in coastal and inland sites of Southern Tanzania, J. Trop. For. Sci. 12, 336 - 347.

[12] P. Mutai, M. Heydenreich, G. Thoithi, G. Mugumbate, K. Chibale and A. Yenesew (2013), 3-Hydroxyisoflavanones from the stem bark of Dalbergia melanoxylon: Isolation, antimycobacterial evaluation and molecular docking studies, Phytochem. Lett. 6, 671 - 675.

[13] P. G. Kareru, A. N. Gachanja, J. M. Keriko and G. M. Kenji, (2008). Antimicrobial activity of some medicinal plants used by herbalists in Eastern province, Kenya, Afr. J. Trad. CAM. 5, 51 - 55.

[14] M. F. Wang, G. Q. Ma, F. Shao, R. H. Liu, L. Y. Chen, Y. Liu, L. Yang and X. W. Meng (2020). Neoflavonoids from the heartwood of Dalbergia melanoxylon, Nat. Prod. Res. 16, 1 - 7. DOI: 10.1080/14786419.2020.1800692

[15] S. F. Wu, F. R. Chang, S. Y. Wang, T. L. Hwang, C. L. Lee, S. L. Chen, C. C. Wu and Y. C. Wu (2011). Anti-inflammatory and cytotoxic neoflavonoids and benzofurans from Pterocarpus santalinus, J. Nat. Prod. 74, 989 - 996.

[16] S. P. Shrestha, Y. Narukawa and T. Takeda (2007). Chemical constituents of Nepalese propolis: isolation of new dalbergiones and related compounds, J. Nat. Med. 61, 73 - 76.

[17] W. B. Eyton, W. D. Ollis, I. O. Sutherland, O. R. Gottlieb, M. T. Magalhaes and L. M. Jackman (1965). The neoflavanoid group of natural products-I: Dalbegiones-A new class of quinones, Tetrahedron 21, 2683 - 2696.

[18] V. Pathak, O. Shirota, S. Sekita, Y. Hirayama, Y Hakamata, T. Hayashi, T. Yanagawa and M. Satake (1997). Antiandrogenic phenolic constituents from Dalbergiaco chinchinensis, Phytochemistry 46, 1219 - 1223.

$$
\begin{gathered}
\text { A } \underset{\text { publications }}{\text { C } 2021 \text { ACG Publications }} \\
\text { C }
\end{gathered}
$$

